\title{
The adult orthodontic patient over 40 years of age: association between periodontal bone loss, incisor irregularity, and increased orthodontic treatment need
}

\author{
Philipp Meyer-Marcotty ${ }^{1}$ (D) Daniela Klenke ${ }^{1} \cdot$ Larissa Knocks $^{1} \cdot$ Petra Santander $^{1} \cdot$ Valentina Hrasky $^{2} \cdot$ Anja $^{\text {Quast }}{ }^{1}$
}

Received: 4 February 2021 / Accepted: 31 March 2021 / Published online: 22 April 2021

(C) The Author(s) 2021

\begin{abstract}
Objectives Adult orthodontic treatment, especially in patients over 40 years, is steadily increasing. One causal factor for the treatment need in this age group is periodontal breakdown. The aim of this study was to detect correlations between periodontal problems and orthodontic parameters in interdisciplinary patients.

Methods This observational, cross-sectional study included 118 patients over 40 years (51 men/67 women; mean age, 58.03 years) classified into three groups according to periodontal breakdown (group I, controls; group II, moderate periodontitis; group III, severe periodontitis). Clinical periodontal and orthodontic parameters as well as the index of orthodontic treatment need (IOTN) were assessed and compared between the groups.

Results A gradual deterioration of all periodontal and orthodontic parameters according to periodontal bone loss (lowest values in group I; highest values in group III) was observed. Especially groups I and III differed significantly regarding the overjet $(p<$ $0.001)$ and the little indices of the maxilla $(p<0.001)$ and mandible $(p<0.010)$. The IOTN was highest in group III: $90 \%$ of the patients with severe periodontitis were classified to have moderate to very great treatment need.

Conclusions The higher the degree of periodontal breakdown was, the more severe were overjet, overbite, irregularity of the anterior teeth, and the orthodontic treatment need.

Clinical relevance Adult patients over 40 years represent a challenge for an orthodontic/periodontal treatment approach with high incidence of pathologic tooth migration, orthodontic treatment need, and periodontal breakdown. Therefore, this special patient collective requires a focus in clinical orthodontics and research.
\end{abstract}

Keyword Orthodontics $\cdot$ Periodontics $\cdot$ Adult $\cdot$ Treatment need $\cdot$ Bone loss

\section{Introduction}

Orthodontic therapy in adults is currently on the increase [1], even if it is not new. In 1723, Pierre Fauchard, one of the first systematic scientists in dentistry, published his observation that straightening teeth is more difficult in adults compared to children [2]. In the fifties of the past century, a thesis for

Philipp Meyer-Marcotty

philipp.meyer-marcotty@med.uni-goettingen.de

1 Department of Orthodontics, University Medical Center Goettingen, Robert-Koch-Str. 40, 37075 Goettingen, Germany

2 Department of Preventive Dentistry, Periodontology and Cariology, University Medical Center Goettingen, Robert-Koch-Str. 40, 37075 Goettingen, Germany board certification by the American Board of Orthodontics focused on adult therapy; it concluded that implementation of adult therapy is important and necessary to broaden the orthodontic spectrum [2]. Furthermore, an orthodontist named Victor Hugo Jackson already discussed successful treatment of adult patients from 40 to 50 years in a textbook from 1904 [2]. Today, these challenging patients ( $\geq 40$ years of age) are no longer a rarity in the daily orthodontic practice and are more and more interested in an orthodontic correction of their accompanying malocclusion [3].

According to Melsen, in adult orthodontics, we must distinguish between "young adults" who should have been treated earlier and "older adults" over 40 years of age with signs of aging and/or gradual deterioration [4]. These patients often present with a secondary malocclusion that has worsened or developed in adulthood. One causative factor could be a 
deterioration of the dentition and the periodontium [5]. Against this background, a close network between orthodontics and periodontics is becoming increasingly important for a successful treatment approach [6-9].

One linking element in diagnostics of both disciplines is pathologic tooth migration (PTM), which is defined as a change in tooth position that occurs when there is a disruption of forces that maintain teeth in a normal relationship. This definition suggests a multifactorial pathophysiology causing tooth migration. A characteristic clinical symptom is incisor flaring [10]. With a reported prevalence of $55.8 \%$ in periodontal patients, the migration, especially of anterior teeth, often represents the primary motivation for adults to consult an orthodontic practice [11].

The main factors known to influence tooth position are the tissues of the periodontium; occlusal factors; soft tissue pressures of the cheek, tongue, and/or lips; and a variety of oral habits. Proffit describes this as "equilibrium theory," which means that all forces affecting the immediate surroundings of a tooth have to be balanced [12]. Keeping this in mind, the interaction between orthodontic malocclusion and periodontal bone level is of special interest for the orthodontic/periodontal scientific community. In recent literature, the need for quantification between malocclusion and periodontal bone loss in adult patients is emphasized [13].

Remarkably, there is a paucity of orthodontic literature on the potentially increasing treatment need of adults at an advanced age. The high prevalence of PTM in these patients leads to the hypothesis that there is a relationship among different degrees of periodontal bone loss, incisor irregularity, and orthodontic treatment need. Therefore, the aims of this study were:

- To detect periodontal and orthodontic parameters in interdisciplinary patients at an advanced age

- To analyze the impact of alveolar bone loss on incisor irregularity

- To quantify the adult orthodontic treatment need in relation to periodontal bone loss

\section{Patients and methods}

This exploratory, observational, cross-sectional study was approved by the Institutional Ethics Committee of the Medical Faculty of the University of Goettingen (ethics number 3/1/ 17). The study was carried out according to the Declaration of Helsinki. All patients participated in the study on a voluntary basis after receiving comprehensive information about the aims and design of the study and signed an informed consent. This report complies with STROBE guidelines for observational studies [14].

\section{Patients}

One hundred twenty-six adult patients were screened for participation in this study. All patients were recruited from the Section of Periodontology of the Department of Preventive Dentistry and referred to the Department of Orthodontics for data acquisition at the University Medical Center Goettingen. The data collection lasted from February 2017 to March 2018; the data were then analyzed by summer 2019 by one single investigator (L.K.). Of the 126 patients initially screened, 118 patients (51 men and 67 women, mean age: 58.03 years) were finally included in the study. The dropouts were due to lack of interest in orthodontics, missing teeth in the front, or an underlying severe malocclusion needing an orthognathic intervention. No additional controls were included after initial data acquisition to avoid potential bias.

The inclusion criteria were age $\geq 40$ years, the presence of six anterior natural teeth in the upper and lower jaw, and no history of trauma. Exclusion criteria were an anterior open bite, history of cleft lip or palate, or a congenital syndrome.

The patients were classified into three groups according to their periodontal disease. Based on the CDC Periodontal Disease Surveillance Working Group, the categories were [15]:

- Group I - control group:

Neither moderate nor severe periodontitis

- Group II-moderate periodontitis:

$\geq 2$ interproximal sites with clinical attachment loss

$(\mathrm{CAL}) \geq 4 \mathrm{~mm}$ or pocket depth $(\mathrm{PD}) \geq 5 \mathrm{~mm}$

- Group III - severe periodontitis:

$\geq 2$ interproximal sites with $\mathrm{CAL} \geq 6 \mathrm{~mm}$ and $\geq 1$ interproximal site with $\mathrm{PD} \geq 5 \mathrm{~mm}$

In each group, periodontal and orthodontic measurements were performed on each tooth from canine to canine in the upper and lower jaw. Figure 1 displays exemplary digitized orthodontic casts for the three patient groups.

\section{Periodontal clinical parameters}

The same person (L.K.) assessed the periodontal clinical parameters for each patient. As metric measurements, pocket depth (PD), clinical attachment loss (CAL), and gingival recession (GR) were analyzed using a periodontal probe. Each tooth of the upper and lower anterior sextant was examined in six areas (mesial, medial, and distal on labial and lingual/palatal tooth surface). In sum, this resulted in 72 measurements per patient per parameter. 
Fig. 1 Three-dimensional digital dental cast of the three analyzed groups classified according to their periodontal bone loss. a Group I: control group - neither moderate nor severe periodontitis b Group II: moderate periodontitis $\longrightarrow 2$ interproximal sites with $\mathrm{CAL} \geq 4 \mathrm{~mm}$ or $\mathrm{PD} \geq 5 \mathrm{~mm}$. c Group III: severe periodontitis$\geq 2$ interproximal sites with CAL $\geq 6 \mathrm{~mm}$ and $\geq 1$ interproximal site with $\mathrm{PD} \geq 5 \mathrm{~mm}$. From a to $\mathrm{c}$, the overjet, the severity of malocclusion, incisor irregularity, and orthodontic treatment need increase a
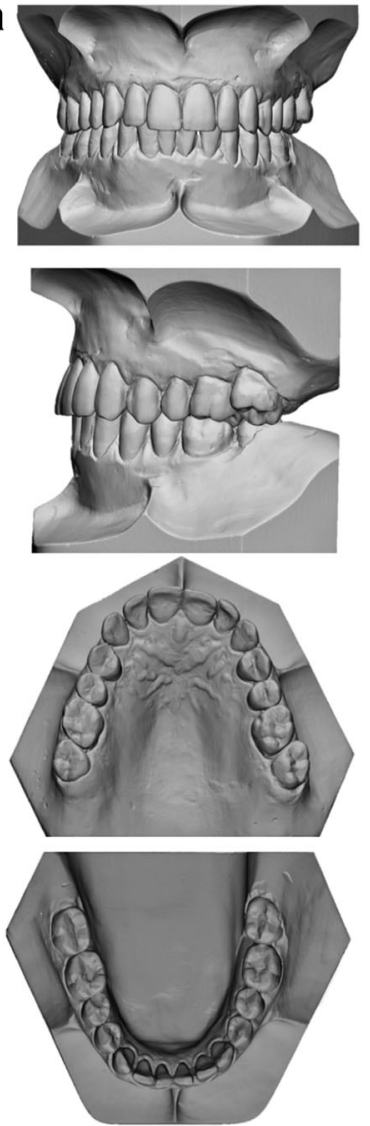

b
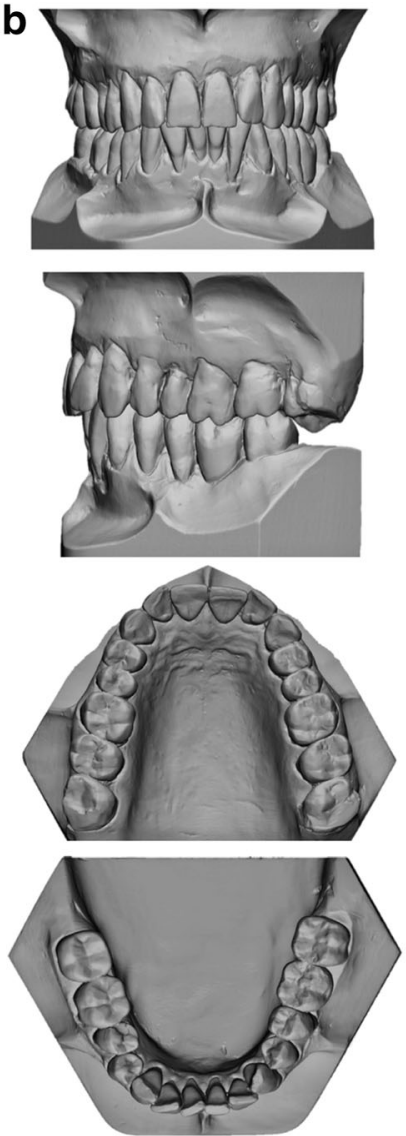

C
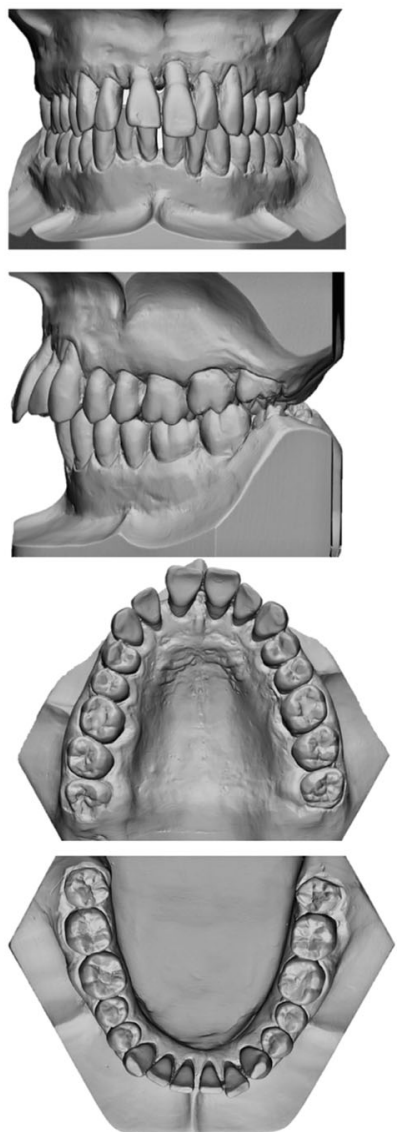

\section{Orthodontic digital model parameters}

To analyze PTM of the anterior teeth, dental casts of the upper and lower jaws were obtained for each patient. For a standardized analysis, the plaster casts were digitized in maximal intercuspidation with a stereophotogrammetric scanner (Zirkonzahn Scanner S300 Ortho (Zirkonzahn S.R.L., Gais, Italy)). The analysis was performed using the 3D software 3matic Research 13.0 (Materialise N.V., Leuven, Belgium). The orthodontic digital model parameters were the overjet and overbite - assessed at the most severe side parallel and perpendicular to the occlusal plane respectively. To quantify the severity of malocclusion, the irregularity index of the mandible was defined by summing up the horizontal measurements of all (five) anatomic contact points between the incisors [16]. The same method was transferred to the maxillary anterior segment.

Additionally, the dental health component (DHC) of the index of orthodontic treatment need (IOTN) [17] was used to objectively quantify the severity of malocclusion. The IOTNDHC grades the indications for treatment considering potential deleterious effects of malocclusion on functional and dental health. It was assessed by one author (L.K.) only, who was trained and experienced in the use of this ordinal scaled index.

\section{Statistics}

Statistical analysis was performed using SPSS Statistics (v.25, IBM, New York, USA). For the orthodontic and periodontal parameters, the mean and $95 \%$ confidence intervals were calculated. To analyze statistical differences between the three groups (controls, patients with moderate periodontitis, and patients with severe periodontitis) a Kruskal-Wallis one-way analysis of variance was performed. Statistically significant differences were followed-up by Mann-Whitney $U$ test to determine which groups contribute to this effect. All results were Bonferroni corrected. Group differences in the IOTNDHC were analyzed by the Fisher's exact test. The association between the Angle class and the degree of periodontal disease was tested by $\chi^{2}$ test. The level of significance was set at $p<0.05$. To determine the error of the method, ten randomly selected 3D data sets were measured again by the same examiner after a 1-week interval, and the Spearman correlations coefficient was calculated. The maximum method error, i.e., the worst Spearman correlation coefficient, was $0.912(p<0.001)$ and was clinically irrelevant. 


\section{Results}

The demographic data for all patients are shown in Table 1 . There was no statistically significant difference between the three groups according to their age $(p=0.071)$. The sex distribution in all three groups was well balanced. An orthodontic treatment during adolescence was documented in $33 \%$ of the patients. Angle classes were equally distributed between the groups (Cramer's V: $0.123 ; p=0.46$ ) with the majority displaying class I.

The results of the descriptive analysis of the periodontal and orthodontic parameters for all patients are demonstrated in Table 2. Statistically significant differences were found for all periodontal parameters among the three different groups. The values of the periodontal parameters increased stepwise with the lowest values for the controls (group I) and the highest values in group III (patients with severe periodontitis). Only the average of recession in the mandible was slightly higher in group II with a mean of $0.55 \mathrm{~mm}$ versus $0.38 \mathrm{~mm}$ in group III. A similar pattern with a gradual increase of the values was found for all orthodontic parameters - again with the lowest values for the controls (group I) and the highest values in group III (patients with severe periodontitis). A

Table 1 Descriptive statistics for all patients according to their group (group I, controls without moderate/severe periodontitis; group II, patients with moderate periodontitis; group III, patients with severe periodontitis)

\begin{tabular}{|c|c|c|c|c|}
\hline $\begin{array}{l}\text { Patients' } \\
\text { characteristics }\end{array}$ & $\begin{array}{l}\text { Group I }(n=39) \\
\text { Controls neither } \\
\text { moderate nor } \\
\text { severe } \\
\text { periodontitis }\end{array}$ & $\begin{array}{l}\text { Group II } \\
(n=39) \\
\text { Patients } \\
\text { with } \\
\text { moderate } \\
\text { periodontitis }\end{array}$ & $\begin{array}{l}\text { Group III } \\
(n=40) \\
\text { Patients } \\
\text { with severe } \\
\text { periodontitis }\end{array}$ & $\Sigma$ \\
\hline Age (years) & $57.36(40 ; 78)$ & $\begin{array}{c}60.97(40 \\
84)\end{array}$ & $\begin{array}{c}55.83(41 ; \\
72)\end{array}$ & $\begin{array}{r}58.03 \\
\quad(4-\end{array}$ \\
\hline \multicolumn{5}{|l|}{ Sex } \\
\hline Men & $31 \%$ & $46 \%$ & $52.5 \%$ & $43 \%$ \\
\hline Women & $69 \%$ & $54 \%$ & $47.5 \%$ & $57 \%$ \\
\hline $\begin{array}{l}\text { History of } \\
\text { orthodontic } \\
\text { treatment in } \\
\text { adolescence }\end{array}$ & $31 \%$ & $21 \%$ & $48 \%$ & $33 \%$ \\
\hline \multicolumn{5}{|c|}{ Angle classification } \\
\hline Class I & $72 \%$ & $69 \%$ & $62.5 \%$ & $68 \%$ \\
\hline Class II & $25.5 \%$ & $26 \%$ & $37.5 \%$ & $29.5 \%$ \\
\hline Class III & $2.5 \%$ & $5 \%$ & $0 \%$ & $2.5 \%$ \\
\hline
\end{tabular}

For age, the mean (minimum; maximum) were reported; for sex, history of orthodontic treatment and angle classification the frequency was calculated; $\sum=$ total

n.s. = not significant significant intergroup difference could be demonstrated for the overjet, Little Index of the mandible, and the maxilla. No significant effect was detected for the overbite.

The intergroup analysis detected significant differences for each group comparison for almost all periodontal parameters. Only the parameter "pocket depth in the mandible" between the control group and group II and the parameters "recession of the maxilla/mandible" between group II and group III showed no significance. The gradually increasing pattern leading to the greatest pathological expression in patients with severe periodontitis was confirmed. The analysis for the orthodontic parameters showed significant differences for the overjet in each group - comparison for group I vs. group II and for group I vs. group III. The lowest values in the control group and the highest values in group III once again confirmed the increasing pathological pattern. In contrast, the Little Indices of the maxilla and mandible were not significantly different between the control group and group II; but when comparing the control group with group III, significant higher values were found in patients with severe periodontitis. The analysis of group II vs. group III showed no significant difference for the orthodontic parameters.

Table 3 shows the results of the descriptive analysis and statistical differences for the IOTN. Group III revealed the highest value of the index. A significant difference for each group comparison was detected between the control group and group III (patients with severe periodontitis). The prevalence of the different IOTN classifications is listed in Table 4. Ninety percent of the patients with severe periodontitis were classified as grade 3 or higher, resulting in moderate to very great treatment need. In contrast, a moderate to very great treatment need was demonstrated in $74.4 \%$ of all patients in group II and only $59.1 \%$ in group I.

\section{Discussion}

In line with the diversification of modern orthodontics, adult therapy is growing rapidly. Not only young adults in their twenties, but patients over 40 years of age are consulting orthodontists more frequently these days. The transition from children and adolescents as the traditional patient cohort in the daily orthodontic clinic to challenging adult patients is already in full swing. In view of this, two principles come more into focus for the orthodontist: (a) the periodontal and orthodontic interrelationship [18] and (b) the adult orthodontic treatment need [3].

In this clinical study, 118 orthodontic patients over 40 years of age were enrolled. Three groups of patients were assigned according to their clinical degree of bone loss, and their periodontal and orthodontic parameters were analyzed. 
Table 2 Descriptive statistics of the periodontal clinical and the orthodontic digital parameters according to their group (group I, controls without moderate/severe periodontitis; group II, patients with moderate periodontitis; group III, patients with severe periodontitis) and corresponding results of the Kruskal-Wallis one-way analysis of variance for the overall comparison between all groups followed up by MannWhitney $U$ test for intergroup analysis

\begin{tabular}{|c|c|c|c|c|c|c|c|c|c|c|c|}
\hline \multirow{3}{*}{$\begin{array}{l}\text { Periodontal } \\
\text { clinical parameters }\end{array}$} & \multirow{2}{*}{\multicolumn{3}{|c|}{$\begin{array}{l}\text { Group I ( } n=39) \\
\text { Controls neither } \\
\text { moderate nor } \\
\text { severe } \\
\text { periodontitis }\end{array}$}} & \multirow{2}{*}{\multicolumn{2}{|c|}{$\begin{array}{l}\text { Group II }(n=39) \\
\text { Patients with } \\
\text { moderate } \\
\text { periodontitis }\end{array}$}} & \multirow{2}{*}{\multicolumn{2}{|c|}{$\begin{array}{l}\text { Group III }(n=40) \\
\text { Patients with } \\
\text { severe } \\
\text { periodontitis }\end{array}$}} & \multirow{2}{*}{$\begin{array}{l}\text { Overall comparison } \\
\text { (group I vs. II vs. III) }\end{array}$} & \multicolumn{3}{|c|}{ Intergroup comparison } \\
\hline & & & & & & & & & \multirow{2}{*}{$\begin{array}{l}\text { Group I } \\
\text { vs. II } \\
- \\
p\end{array}$} & \multirow{2}{*}{$\begin{array}{l}\text { Group I } \\
\text { vs. III } \\
p\end{array}$} & \multirow{2}{*}{$\begin{array}{l}\text { Group II } \\
\text { vs III } \\
p\end{array}$} \\
\hline & Unit & Mean & $95 \% \mathrm{CI}$ & Mean & $95 \% \mathrm{CI}$ & Mean & $95 \% \mathrm{CI}$ & $p$ & & & \\
\hline Pocket depth $\max ^{+}$ & $\mathrm{mm}$ & 1.68 & {$[1.56-1.79]$} & 1.91 & {$[1.77-2.05]$} & 2.96 & {$[2.69-3.22]$} & $<0.001 * * *$ & $0.012 *$ & $\begin{array}{c}< \\
0.001- \\
* * *\end{array}$ & $\begin{array}{c}< \\
0.001- \\
* * *\end{array}$ \\
\hline $\begin{array}{l}\text { Pocket depth } \\
\text { mand }^{++}\end{array}$ & $\mathrm{mm}$ & 1.42 & {$[1.33-1.51]$} & 1.58 & {$[1.45-1.71]$} & 2.56 & {$[2.29-2.83]$} & $<0.001 * * *$ & $\begin{array}{r}0.076 \\
\text { n.s. }\end{array}$ & $\begin{array}{l}< \\
0.001- \\
* * *\end{array}$ & $\begin{array}{c}< \\
0.001- \\
* * *\end{array}$ \\
\hline Recession $\max ^{+}$ & $\mathrm{mm}$ & 0.03 & {$[0.01-0.05]$} & 0.30 & {$[0.18-0.43]$} & 0.37 & {$[0.27-0.46]$} & $<0.001 * * *$ & $\begin{array}{c}< \\
0.001- \\
* * *\end{array}$ & $\begin{array}{c}< \\
0.001- \\
* * *\end{array}$ & 0.105 \\
\hline Recession mand ${ }^{++}$ & $\mathrm{mm}$ & 0.07 & {$[0.04-0.10]$} & 0.55 & {$[0.36-0.73]$} & 0.38 & {$[0.29-0.48]$} & $<0.001 * * *$ & $\begin{array}{c}< \\
0.001- \\
* * *\end{array}$ & $\begin{array}{c}< \\
0.001- \\
* * *\end{array}$ & 0.533 \\
\hline $\mathrm{CAL} \max ^{+}$ & $\mathrm{mm}$ & 1.71 & {$[1.59-1.82]$} & 2.21 & {$[2.08-2.34]$} & 3.32 & {$[3.02-3.61]$} & $<0.001 * * *$ & $\begin{array}{c}< \\
0.001- \\
* * *\end{array}$ & $\begin{array}{c}< \\
0.001- \\
* * *\end{array}$ & $\begin{array}{c}< \\
0.001- \\
* * *\end{array}$ \\
\hline CAL mand ${ }^{++}$ & $\mathrm{mm}$ & 1.49 & {$[1.40-1.58]$} & 2.13 & [1.96-2.29] & 2.94 & {$[2.65-3.24]$} & $<0.001 * * *$ & $\begin{array}{c}< \\
0.001- \\
* * *\end{array}$ & $\begin{array}{c}< \\
0.001- \\
* * *\end{array}$ & $\begin{array}{l}< \\
0.001- \\
* * *\end{array}$ \\
\hline \multicolumn{12}{|c|}{ Orthodontic digital parameters } \\
\hline Overjet & $\mathrm{mm}$ & 2.60 & [2.10-3.08] & 3.37 & [2.73-4.02] & 4.38 & [3.58-5.17] & $<0.001 * * *$ & $0.026^{*}$ & $\begin{array}{c}< \\
0.001- \\
* * *\end{array}$ & $\begin{array}{r}0.051 \\
\text { n.s. }\end{array}$ \\
\hline Overbite & $\mathrm{mm}$ & 2.95 & [2.33-3.56] & 3.10 & [2.68-3.52] & 3.45 & [2.81-4.09] & 0.475 n.s. & - & - & - \\
\hline Little Index $\max ^{+}$ & $\mathrm{mm}$ & 1.76 & [1.22-2.30] & 2.56 & [1.77-3.36] & 4.06 & [2.96-5.16] & $0.001 * *$ & $\begin{array}{r}0.511 \\
\text { n.s. }\end{array}$ & $0.001 * *$ & $\begin{array}{r}0.062 \\
\text { n.s. }\end{array}$ \\
\hline $\begin{array}{l}\text { Little Index } \\
\text { mand }^{++}\end{array}$ & $\mathrm{mm}$ & 2.71 & [1.97-3.44] & 3.78 & {$[2.85-4.72]$} & 4.33 & {$[3.46-5.19]$} & $0.012 *$ & $\begin{array}{r}0.187 \\
\text { n.s. }\end{array}$ & $0.010 * *$ & $\begin{array}{r}0.875 \\
\text { n.s. }\end{array}$ \\
\hline
\end{tabular}

The mean and 95\% confidence Interval (CI) were reported; significance level was set at $p<0.05$, adjusted by Bonferroni correction

${ }^{+}$maxilla

${ }^{++}$mandibula; $C A L$ clinical attachment level

Kruskal-Wallis and Mann-Whitney-U test: $n . s$. not significant

$* p<0.05$

$* * p<0.01$

$* * * p<0.001$

\section{Periodontal parameters}

Using the CAL as the main periodontal parameter, the control group, the patients with moderate periodontitis, and the patients with severe periodontitis could be clearly separated from each other. A significant difference was shown in both the maxilla and in the mandible. This is in accordance with the working group of the Centers for Disease Control and Prevention and the American Academy of Periodontology
(CDC/AAP) in 2003, where thresholds were defined for severe periodontitis with a CAL $\geq 6 \mathrm{~mm}$ and for moderate periodontitis with a CAL $\geq 4 \mathrm{~mm}[15,19]$. They defined the measurement of the CAL as the gold standard for diagnostics in periodontics. Furthermore, CAL revealed to be a more accurate measure of disease history and disease progression than PD alone. This is underpinned by the results of this study: a highly significant difference in PD in the mandible and maxilla was shown in patients with severe periodontitis vs. 
Table 3 Descriptive statistics for the Index of Orthodontic Treatment Need-Dental Health Category (IOTN-DHC) of all patients according to their groups (group I, controls without moderate/severe periodontitis; group II, patients with moderate periodontitis; group III, patients with severe periodontitis) and the results of the overall and intergroup comparison by Fisher's exact test

\begin{tabular}{|c|c|c|c|c|c|c|c|}
\hline \multirow{3}{*}{$\begin{array}{l}\text { Orthodontic digital } \\
\text { parameter }\end{array}$} & \multirow{2}{*}{$\begin{array}{l}\text { Group I }(n=39) \\
\text { Controls neither } \\
\text { moderate nor } \\
\text { severe } \\
\text { periodontitis }\end{array}$} & \multirow{2}{*}{$\begin{array}{l}\text { Group II } \\
(n=39) \text { Patients } \\
\text { with moderate } \\
\text { periodontitis }\end{array}$} & \multirow{2}{*}{$\begin{array}{l}\text { Group III } \\
(n=40) \text { Patients } \\
\text { with severe } \\
\text { periodontitis }\end{array}$} & \multirow{2}{*}{$\begin{array}{l}\text { Overall comparison (group I } \\
\text { vs. II vs. III) }\end{array}$} & \multicolumn{3}{|c|}{ Intergroup comparison } \\
\hline & & & & & $\begin{array}{l}\text { Group I } \\
\text { vs II }\end{array}$ & $\begin{array}{l}\text { Group I } \\
\text { vs. III }\end{array}$ & $\begin{array}{l}\text { Group II } \\
\text { vs. III }\end{array}$ \\
\hline & Mean $95 \%$ CI & Mean $95 \% \mathrm{CI}$ & Mean $95 \% \mathrm{CI}$ & $p$ & $p$ & $p$ & $p$ \\
\hline IOTN-DHC & 2.85 [2.58-3.11] & 3.18 [2.91-3.45] & 3.45 [3.21-3.69] & $0.022 *$ & 0.205 & $0.005 * *$ & 0.165 \\
\hline
\end{tabular}

The mean and 95\% confidence interval (CI) were reported; significance level was set at $p<0.05$, adjusted by Bonferroni correction

Fisher's exact test: n.s. not significant

$* p<.05$

$* * p<.01$

$* * * p<.001$

patients with moderate periodontitis and between the control group and patients with severe periodontitis. However, no significant difference was detectable between the control group and patients with moderate periodontitis in the mandible, and the difference in the maxilla was only marginal. This less indicative group classification by PD could be explained by the age of the patients enrolled in this study: Because the focus fell on patients over 40 years of age, no direct correlation between PD and CAL compared to younger adults could be analyzed. It has been shown that in (post-) middle age patients, gingival recessions increase more rapidly than $\mathrm{PD}$ [15]; therefore, CAL and PD no longer correlate in adults over the age of 40 . In this respect, the parameters selected for the study were confirmed.

\section{Orthodontic parameters}

The parameters overjet and overbite increased progressively in all three groups. Regarding the periodontal breakdown, the overjet was $30 \%$ higher in patients with moderate periodontitis and $69 \%$ higher in patients with severe periodontitis compared to the controls. The overbite was $5 \%$ and $17 \%$ higher, respectively. In summary, the higher the degree of periodontal breakdown, the more severe the overjet and overbite are in patients over 40 years of age. These results, which are typical findings in the daily clinical practice, were now quantified by our study in adult orthodontic patients. However, it has to be kept in mind that the overjet and overbite are also strongly associated with the Angle classes. A lack of incisor contact may favor dental elongation, especially in combination with periodontal breakdown. Therefore, we aimed for equally distributed Angle classification among the groups.

The herein observed pathophysiology is explained by the fact that the degeneration of the periodontium and the alveolar boundary results in PTM [20]. The clinical consequence is an initial PTM, which can be detected as "flaring out" of the upper frontal teeth in patients with severe periodontitis [21, 22]. This is substantiated by the findings in our study, in which a primary increase of "flaring out" automatically resulted in a higher overjet in patients with moderate to severe periodontitis. Thereby, an increase in periodontal disease seemed to be associated with deterioration of overjet but not overbite. These results are in accordance with recent published literature [23].

In addition to periodontal breakdown, another factor contributing to "flaring out" of the upper teeth could be the surrounding soft tissues (e.g., lower lip) [12]. Even though the surrounding forces by the soft tissues are very light, it has been
Table 4 Prevalence of the index of orthodontic treatment need (IOTN) classifications for the control group (group I), for patients with moderate periodontitis (group II), and for patients with severe periodontitis (group III)

\begin{tabular}{llllc}
\hline $\begin{array}{l}\text { Classification IOTN- } \\
\text { value }\end{array}$ & $\begin{array}{l}\text { Clinical } \\
\text { implication }\end{array}$ & $\begin{array}{l}\text { Prevalence in } \% \\
\text { group I }\end{array}$ & $\begin{array}{l}\text { Prevalence in } \% \\
\text { group II }\end{array}$ & $\begin{array}{l}\text { Prevalence in \% } \\
\text { group III }\end{array}$ \\
\hline 1 & None & 0 & 0 & 0 \\
2 & - & 41 & 25.6 & 10 \\
3 & Little & & 30.8 & 40 \\
4 & Moderate & 33.3 & 43.6 & 45 \\
5 & - & 25.6 & 0 & 5 \\
\hline
\end{tabular}


documented that forces as light as $1.0 \mathrm{~g}$ produced by the facial tissue are sufficient to initiate displacement of upper or lower incisors [24]. Therefore, the lower lip has to be regarded as another progressive factor for developing more severe malocclusions: when the increased overjet is associated with lower lip dysfunction and periodontal bone loss, the upper incisors protrude more and more due to the lip pressure. Thus, a vicious circle (periodontal breakdown, flaring out, lip dysfunction) is developing in orthodontic patients with moderate/ severe periodontitis.

Another orthodontic parameter which could be affected by periodontal bone loss is the irregularity of the anterior teethexpressed by the Little Index. In our study, the Little Index increased in the maxilla and mandible stepwise from group I to group III, resulting in a significant difference between the controls and patients with severe periodontal bone loss. These findings are contrary to previous literature where no association was found between periodontal bone loss and crowding [25]. This could be attributed to the fact that in the present study, the age range of the included patients was more focused on $\geq 40$ years of age, whereas the previous study included patients from 21 up to 55 years of age.

When comparing the Little Index between the maxilla and mandible, the mandible revealed more irregularity of the frontal teeth in each group. This is confirmed by recent literature showing irregularity in the mandibular incisor area to be associated with a distinct localized periodontal breakdown [26]. The reason could be the characteristic morphology with thin bone or previously existing fenestration/dehiscence and root proximity, resulting in a higher sensitivity to PTM.

However, the differences in the Little Index between both jaws waned with increasing bone loss. Patients with severe periodontitis had only a minimal difference between maxillary and mandibular irregularity of the frontal teeth. This effect may be explained by the different bone architecture in the maxilla with more cancellous bone, even in the anterior alveolar region $[27,28]$. This anterior alveolar region seems more sensitive to PTM when bone loss is increasing. Thus, by exceeding a certain threshold of bone loss, a similar pathological mesial migration of the teeth is observed in the mandible and maxillary arch.

\section{Index of orthodontic treatment need}

Up to now, there is no data describing the orthodontic treatment need of adults in a focused patient group over 40 years of age with differing degrees of bone loss. Only one study has investigated the orthodontic treatment need using the esthetic component (AC) of the IOTN in a similar patient cohort (mean age 56.8 years; moderate to severe periodontitis) [3]. In this former study, one-third of the patients showed a moderate to definite treatment need; but this study focused only on dental attractiveness, i.e., the esthetic component. In contrast, the present study analyzed the Dental Health Component (DHC) of the IOTN taking potential deleterious effects of malocclusion on the health and functioning of the dentition into account.

The IOTN-DHC revealed a significantly higher treatment need in patients with severe periodontitis compared to patients with moderate/no periodontal bone loss. Again, this may be associated with the statistically higher degree of PTM because of severe periodontal bone loss [29]. Moreover, it is known that the risk of PTM rises by a factor of more than 2.5 if there is an increase in bone loss. This uncontrolled tooth migration results in a higher IOTN classification, so that $90 \%$ of the patients with severe bone loss were classified as grade 3 or higher, which means moderate to very great treatment need. Keeping in mind that the IOTN-DHC has a reproducibility of $93 \%$ [17], these data indicate the necessity for a reorientation in adult orthodontic treatment, focusing on patients with advanced age.

\section{Conclusions}

Adult patients with an advanced age represent a challenge for interdisciplinary orthodontic/periodontal treatment approaches. The findings of our study with patients over 40 years of age showed that the higher the degree of periodontal breakdown is,

- The more severe is the overjet and overbite

- The more severe is the irregularity of the anterior teeth in the maxilla and the mandible

- The higher is the reported treatment need compared to patients with no periodontal bone loss.

Therefore, this special patient cohort will require a particular focus in clinical orthodontics and research in the near future.

Abbreviations PTM, pathologic tooth migration; PD, pocket depth; CAL, clinical attachment loss; GR, gingival recession; DHC, dental health component; IOTN, index of orthodontic treatment need; CDC, Centers for Disease Control and Prevention; AAP, American Academy of Periodontology; AC, esthetic component

Author contribution All authors contributed to the conception of the study, data acquisition, analysis and interpretation, and drafting of the manuscript. All authors revised the article critically and gave final approval of the submitted version.

Funding Open Access funding enabled and organized by Projekt DEAL.

\section{Declarations}

Ethics approval All procedures performed in this study involving human participants were in accordance with the ethical standards of the 
institutional research committee and with the 1964 Helsinki declaration and its later amendments or comparable ethical standards.

Informed consent Informed consent was obtained from all individual participants included in the study.

Conflict of interest The authors declare no competing interests.

Open Access This article is licensed under a Creative Commons Attribution 4.0 International License, which permits use, sharing, adaptation, distribution and reproduction in any medium or format, as long as you give appropriate credit to the original author(s) and the source, provide a link to the Creative Commons licence, and indicate if changes were made. The images or other third party material in this article are included in the article's Creative Commons licence, unless indicated otherwise in a credit line to the material. If material is not included in the article's Creative Commons licence and your intended use is not permitted by statutory regulation or exceeds the permitted use, you will need to obtain permission directly from the copyright holder. To view a copy of this licence, visit http://creativecommons.org/licenses/by/4.0/.

\section{References}

1. Melsen B (2016) The role of orthodontics in the regeneration of the degenerated dentition. J Oral Rehabil 43:226-237. https://doi.org/ 10.1111 joor. 12365

2. Goldstein MC (1953) Adult orthodontics Am J Orthod Dentofacial Orthop: 400-24

3. Hirschfeld J, Reichardt E, Sharma P et al (2019) Interest in orthodontic tooth alignment in adult patients affected by periodontitis: a questionnaire-based cross-sectional pilot study. J Periodontol 90: 957-965. https://doi.org/10.1002/JPER.18-0578

4. Melsen B (2012) Adult Orthodontics, 1. edn. Wiley-Blackwell, s.1.

5. Reichert C, Hagner M, Jepsen $S$ et al (2011) Interfaces between orthodontic and periodontal treatment: their current status. J Orofac Orthop 72:165-186. https://doi.org/10.1007/s00056-011-0023-6

6. Cardaropoli D, Re S, Corrente G et al (2001) Intrusion of migrated incisors with infrabony defects in adult periodontal patients. Am J Orthod Dentofacial Orthop 120:671-675; quiz 677. https://doi.org/ 10.1067/mod.2001.119385

7. Kokich VG (2011) The key to adult orthodontics. Am J Orthod Dentofacial Orthop 139:289. https://doi.org/10.1016/j.ajodo.2011. 02.002

8. Mathews DP, Kokich VG (1997) Managing treatment for the orthodontic patient with periodontal problems. Semin Orthod 3:2138. https://doi.org/10.1016/s1073-8746(97)80037-0

9. Re S, Corrente G, Abundo R et al (2000) Orthodontic treatment in periodontally compromised patients: 12 -year report. Int $\mathrm{J}$ Periodontics Restorative Dent 20:31-39

10. Corrente G, Abundo R, Re S et al (2003) Orthodontic movement into infrabony defects in patients with advanced periodontal disease: a clinical and radiological study. J Periodontol 74:11041109. https://doi.org/10.1902/jop.2003.74.8.1104

11. Brunsvold MA (2005) Pathologic tooth migration. J Periodontol 76:859-866. https://doi.org/10.1902/jop.2005.76.6.859

12. Proffit WR (1978) Equilibrium theory revisited: factors influencing position of the teeth. Angle Orthod 48:175-186. https://doi.org/10. 1043/0003-3219(1978)048<0175:ETRFIP >2.0.CO;2

13. Ngom PI, Diagne F, Benoist HM et al (2006) Intraarch and interarch relationships of the anterior teeth and periodontal conditions. Angle Orthod 76:236-242. https://doi.org/10.1043/ 0003-3219(2006)076[0236:IAIROT]2.0.CO;2

14. von Elm E, Altman DG, Egger M et al (2007) The Strengthening the Reporting of Observational Studies in Epidemiology (STROBE) statement: guidelines for reporting observational studies. Lancet 370:1453-1457. https://doi.org/10.1016/S01406736(07)61602-X

15. Page RC, Eke PI (2007) Case definitions for use in populationbased surveillance of periodontitis. J Periodontol 78(Suppl 7S): 1387-1399. https://doi.org/10.1902/jop.2007.060264

16. Little RM (1975) The irregularity index: a quantitative score of mandibular anterior alignment. Am J Orthod Dentofacial Orthop 68:554-563. https://doi.org/10.1016/0002-9416(75)90086-x

17. Brook PH, Shaw WC (1989) The development of an index of orthodontic treatment priority. Eur J Orthod 11:309-320. https:// doi.org/10.1093/oxfordjournals.ejo.a035999

18. Zasciurinskiene E, Baseviciene N, Lindsten R et al (2018) Orthodontic treatment simultaneous to or after periodontal causerelated treatment in periodontitis susceptible patients. Part I: Clinical outcome. A randomized clinical trial. J Clin Periodontol 45:213-224. https://doi.org/10.1111/jcpe.12835

19. Armitage GC (2003) Diagnosis of periodontal diseases. J Periodontol 74:1237-1247. https://doi.org/10.1902/jop.2003.74.8. 1237

20. Towfighi PP, Brunsvold MA, Storey AT et al (1997) Pathologic migration of anterior teeth in patients with moderate to severe periodontitis. J Periodontol 68:967-972. https://doi.org/10.1902/jop. 1997.68.10.967

21. Cao T, Xu L, Shi J et al (2015) Combined orthodontic-periodontal treatment in periodontal patients with anteriorly displaced incisors. Am J Orthod Dentofacial Orthop 148:805-813. https://doi.org/10. 1016/j.ajodo.2015.05.026

22. Xie Y, Zhao Q, Tan Z et al (2014) Orthodontic treatment in a periodontal patient with pathologic migration of anterior teeth. Am J Orthod Dentofacial Orthop 145:685-693. https://doi.org/10. 1016/j.ajodo.2013.08.018

23. Geiger AM (2001) Malocclusion as an etiologic factor in periodontal disease: a retrospective essay. Am J Orthod Dentofacial Orthop 120:112-115. https://doi.org/10.1067/mod.2001.114537

24. Lear CS, Moorrees CF (1969) Buccolingual muscle force and dental arch form. Am J Orthod Dentofacial Orthop 56:379-393. https:// doi.org/10.1016/s0002-9416(69)80005-9

25. Geiger AM, Wasserman BH (1976) Relationship of occlusion and periodontal disease: part IX-incisor inclination and periodontal status. Angle Orthod 46:99-110. https://doi.org/10.1043/00033219(1976)046<0099:ROOAPD>2.0.CO;2

26. Alsulaiman AA, Kaye E, Jones J et al (2018) Incisor malalignment and the risk of periodontal disease progression. Am J Orthod Dentofacial Orthop 153:512-522. https://doi.org/10.1016/j.ajodo. 2017.08.015

27. Saffar JL, Lasfargues JJ, Cherruau M (1997) Alveolar bone and the alveolar process: the socket that is never stable. Periodontol 2000 13:76-90. https://doi.org/10.1111/j.1600-0757.1997.tb00096.x

28. Coskun I, Kaya B (2019) Relationship between alveolar bone thickness, tooth root morphology, and sagittal skeletal pattern: a cone beam computed tomography study. J Orofac Orthop 80:144-158. https://doi.org/10.1007/s00056-019-00175-9

29. Martinez-Canut P, Carrasquer A, Magan R et al (1997) A study on factors associated with pathologic tooth migration. J Clin Periodontol 24:492-497. https://doi.org/10.1111/j.1600-051x. 1997.tb00217.x

Publisher's note Springer Nature remains neutral with regard to jurisdictional claims in published maps and institutional affiliations. 